\title{
Studying the fidelity of implementation of an intrinsic motivation course con- version
}

\section{Dr. Geoffrey L Herman, University of Illinois, Urbana-Champaign}

Dr. Geoffrey L. Herman is a visiting assistant professor with the Illinois Foundry for Innovation in Engineering Education at the University of Illinois at Urbana-Champaign and a research assistant professor with the Department of Curriculum \& Instruction. He earned his Ph.D. in Electrical and Computer Engineering from the University of Illinois at Urbana-Champaign as a Mavis Future Faculty Fellow and conducted postdoctoral research with Ruth Streveler in the School of Engineering Education at Purdue University. His research interests include creating systems for sustainable improvement in engineering education, promoting intrinsic motivation in the classroom, conceptual change and development in engineering students, and change in faculty beliefs about teaching and learning. He serves as the webmaster for the ASEE Educational Research and Methods Division.

\section{Katherine Anne Earl, University of Illinois at Urbana-Champaign}

Katherine Earl is a graduate student in the Department of Education's Counseling Psychology Program at the University of Illinois at Urbana-Champaign; earl2@illinois.edu.

\section{Dong San Choi, University of Illinois, Urbana-Champaign}

Dong San Choi is a graduate student in the Department of Electrical and Computer Engineering at University of Illinois at Urbana-Champaign; choi88@illinois.edu. 


\title{
Creating Scalable Reform in Engineering Education Through Low-Cost Intrinsic Motivation Course Conversions of Engineering Courses
}

\begin{abstract}
The low-cost intrinsic motivation (IM) course conversion project is an effort to improve the quality of undergraduate engineering education by creating course designs that promote students' intrinsic motivation to learn while keeping the time and financial investments for those course designs low. Because of the project's explicit goal of creating a course design method that facilitates translation of practices across instructors and courses, a critical test of the method is the fidelity of implementation and outcomes across instructors. In prior papers, we have presented how the first IM-converted course promoted students' intrinsic motivation to learn and improved their conceptual understanding of the course content. In this paper, we present a replication study that explores and contrasts the implementation and outcomes of the second offering of the IM-converted course when it was taught by different instructors. We use a mixedmethods comparative case study to describe and contrast the two offerings of the course. We present a portion of these case study analyses, contrasting the data and results from course syllabi, student interviews, and course climate surveys.
\end{abstract}

\section{Introduction}

The engineering education community has become increasingly aware that improving the adoption of research-based instructional strategies (RBIS) is a complex process, meriting its own research and development efforts ${ }^{1,2}$. While there are plenty of evidence-based RBIS in engineering education, their adoption remains low ${ }^{1}$. Faculty time and student resistance are commonly cited barriers to the adoption of $\mathrm{RBIS}^{2,3}$, so we developed the low-cost intrinsic motivation (IM) course conversion as an attempt to create course designs that promote students' intrinsic motivation to learn while keeping the time and financial investments for those course designs low. If students become intrinsically-motivated to learn, they may become change agents who demand different instruction. If course designs are demonstrably adoptable and feasible, they may be more attractive to faculty to adopt. Critically, the focus on motivation rather than content or specific pedagogies can lead to better learning as students who are intrinsically motivated to learn adopt strategies for deeper learning and persist longer in their learning when encountering difficulties.

Because of the project's explicit goal of creating a course design method that facilitates translation of practices across instructors and courses, a critical test of the method is the fidelity of implementation and outcomes across instructors. In prior papers we have presented how the first IM-converted course promoted students' intrinsic motivation to learn and improved their conceptual understanding of the course content. These initial course offerings were designed and offered or supported by the project lead. Results from the Fall 2012 offering were promising as the intended outcomes (improvements in students' motivation and positive faculty experiences) were achieved. To test the robustness of this method, that IM-converted course was offered a second time during the Fall 2013 term with different instructors who had not taught the course with these methods. In this paper, we present a replication study that explores and contrasts the implementation and outcomes of these two offerings of the IM-converted course. We used a 
mixed-methods comparative case study to describe and contrast the two offerings of the course. We present a portion of these case study analyses, contrasting the data and results from course syllabi, student interviews, and course climate surveys.

\section{Background}

Faculty naturally adopt ad hoc course design methods that emphasize sequencing a series of isolated topics that conform to departmental pressures and mandates ${ }^{4}$. These types of course designs typically result in shallow cognitively-focused learning outcomes such as "remembering” or "understanding." Traditional course design methods such as Backwards Course Design ${ }^{5}$ and its direct successor Idea-Based Learning ${ }^{4}$ promote cognitively-focused learning outcomes that describe deeper learning activities such as “evaluate” or "synthesize.” In accordance with these types of methods, many reform efforts focus on helping faculty adopt interactive engagement (IE) or active learning pedagogies that redefine the professor's role from a "sage-on-the-stage" to a "guide-on-the-side 6 ." Indeed, these IE pedagogies leverage greater student interactions to develop "deep learning” that leads to expertise in a variety of engineering skills and knowledge rather than surface learning such as fact memorization or rote problem solving ${ }^{6-12}$. Although interactive engagement pedagogies are effective, adoption of these RBIS remains low among faculty for a variety of reasons such as a lack of time or training ${ }^{2}$.

The Goldberg-Laffer curve (Figure 1) hypothesizes that when we attempt to move from "sage-on-the-stage” lectures to "guide-on-the-side” IE pedagogies, we can increase student engagement, but only by increasing the time and energy costs to faculty ${ }^{13}$. It further hypothesizes that there is an "IM space jump" through which we could increase student engagement in the classroom with minimal or no cost to faculty. Instead of faculty-driven change, intrinsicallymotivated students drive change in the classroom and create pedagogical and educational reform. To achieve this "space jump," we need course design methods that emphasize increasing students' intrinsic-motivation to learn, leading to the development of the intrinsic motivation course conversion project.

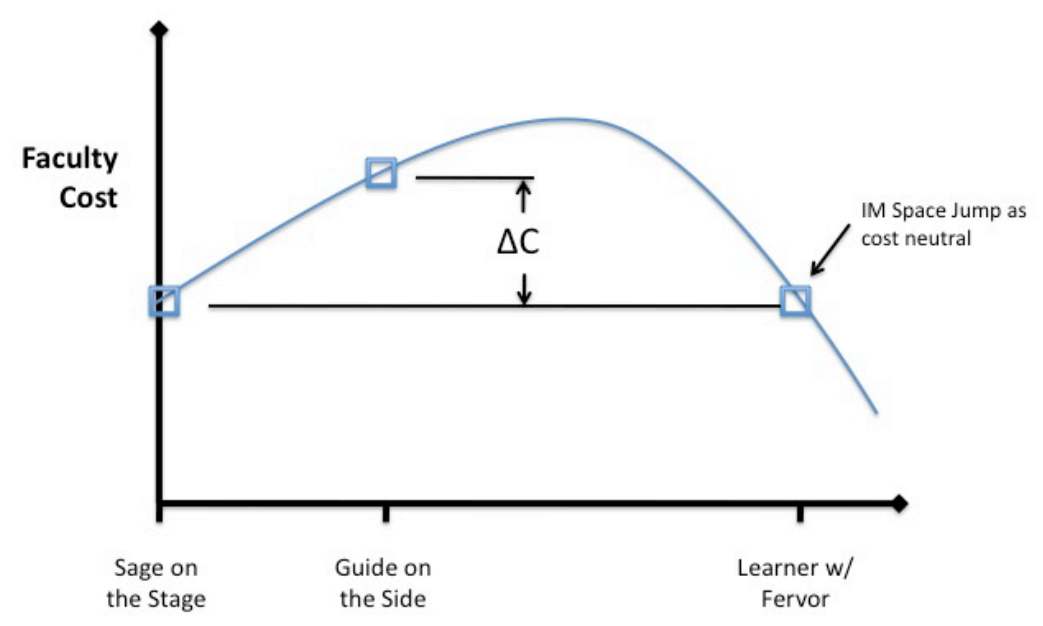

\% Student Engagement

Figure 1: Goldberg-Laffer curve ${ }^{13}$ 


\subsection{Student motivation}

Students' motivation to learn ranges on a continuum from amotivation through extrinsic motivation (receiving rewards such as grades, complying with rules) to intrinsic motivation (satisfying personal interests, or deriving from the inherent value of an activity) ${ }^{14,15}$. Students tend to learn more when they are intrinsically motivated to learn ${ }^{16}$. Intrinsic motivation is supported when students' needs for a sense of competence (mastery), autonomy, relatedness, and purpose are met ${ }^{14,15,17}$. Although intrinsic motivation can be supported by meeting any of these needs, supporting students' sense of autonomy is perhaps the most effective way of improving students' motivation ${ }^{17}$. Intrinsic motivation can be supported in any classroom or by any instructor regardless of the predominant teaching mode (i.e., traditional lecture versus interactive engagement pedagogies versus problem-based learning), but some learning environments foster autonomy better than others.

Despite the importance of motivation in learning, it seldom has served as the focal point of pedagogical change in engineering ${ }^{18}$.

\subsection{Context of the IM converted course}

Both IM course conversions described in this paper took place in Computer Engineering I (CompE I) at the University of Illinois at Urbana-Champaign - a large, research-intensive university. CompE I enrolls 200 students per semester. Around $80 \%$ of students are male each semester and the majority of students identify as White or Asian. The course is required for electrical engineering and computer engineering students. Most of these students take the course during their second year of study. The course has two one-hour lectures per week (one hour each on Mondays and Wednesdays) and one one-hour discussion section per week (on Thursdays). The overarching goal of the course is to teach students about how to design digital logic components and analyze or modify existing computer architectures.

\section{Evaluation methods}

The evaluation of the two IM course conversions relied on a mixed-methods design. Surveys were used to measure students' perception of the course's overall support for their intrinsic motivation to learn. Interviews were used to develop deeper insights into how specific elements of the course impacted students' intrinsic motivation to learn.

\subsection{Quantitative methods}

The Learning Climate Questionnaire (LCQ) measures the IM-supportiveness of a learning environment. The LCQ uses fifteen, seven-point Likert scale item to provide a single numerical rating of the learning climate. These items assess the instructor's support of students' decisions (autonomy), affirmation of students' ability (competence), approachability (relatedness), and communication of purpose (purpose). The LCQ was administered at the end of each semester to measure each course's climate.

Statistical differences between semesters were assessed using Welch’s t-test. Effect sizes were measured using Cohen’s d. 


\subsection{Qualitative methods}

All students who had taken the converted CompE I course during Fall 2013 were invited to participate in an hour-long interview and compensated $\$ 10$ for their time. A narrative approach ${ }^{20-24}$ was taken when conducting interviews where students were asked to tell their story of the course from the first day of class to the completion of the final examination. When certain portions of the course were not mentioned in their narrative, students were asked if they remembered those portions and were prompted to elaborate. Ten students volunteered to participate in audio recorded interviews. All the interviews were transcribed and student responses were kept anonymous to encourage students to express their honest opinions of the course. The three authors were not involved in teaching the course or grading students work. Interview protocols and analysis methods were approved by IRB review.

The first round of coding was done by the three authors independently. An a priori coding scheme was developed based on student motivation involving of autonomy, competence, related, and purpose. Open-coding was used to capture additional information regarding what students did and how they perceived their experience (i.e. choosing projects, attitude towards team members, etc). The second round of coding was done collaboratively to go over each of the ten interviews line by line to define codes and to discuss discrepancies. For discrepancies, authors would defend their interpretation of the text and dialogue ensued until a consensus about the code was reached. Once the second round of coding was completed, the authors independently looked for themes based on the codes. As different themes emerged from different authors, authors were assigned to investigate themes that were not their own to confirm whether there was enough textual evidence to support the theme in question.

\section{Design and outcomes of the Fall 2013 IM course conversion}

In depth descriptions of the Fall 2012 IM Course Conversion (IM2012) appear in previous publications ${ }^{19}$. We provide only those details of the IM2012 course design and outcomes that inform its direct comparison with the Fall 2013 IM Course Conversion (IM2013).

\subsection{Design of IM2012}

During the first class of IM2012, students were given a short lecture about the nature of intrinsic motivation to learn and were told about the course's intentions to promote their intrinsic motivation to learn. Students were then given a list of short, challenge-based projects that the students could choose to complete during the first five weeks of the semester. Projects were chosen to represent a range of potential applications of the course content ranging from the design of computer architecture components to the design of communication systems to the design of controller for a frozen yogurt dispenser. Students completed a short survey that indicated their availability for team meetings during the semester and their rankings for which projects they wanted to complete. The survey also gave students the option to propose their own projects if they could assemble a team of like-minded students. Teams of 4 or 5 were assembled so that each student got to complete their first- or second-choice project. The assembly of teams around chosen projects was intended to promote students' senses of autonomy and purpose. 
Lectures were co-taught by two faculty instructors. Each instructor delivered lectures with whatever method seemed best to them. During discussion sections, students completed collaborative problem-solving worksheets.

In lieu of turning in written homework and having it graded, teams scheduled one-hour weekly consultations with a teaching assistant or instructor during which they discussed written homework problems and received coaching on their chosen projects. These sessions were intended to shift students' attention from extrinsic rewards such as grades and toward intrinsic learning interactions such as receiving and responding to feedback to build competence and supporting the learning of their peers to support relatedness.

To again promote students' autonomy after the completion of their first projects, students were given the option to maintain or dissolve their teams for the remainder of the semester. All students opted to maintain their teams. Students completed two more projects with these teams with five weeks devoted to each project. Students were given increasing levels of autonomy in determining the topic and deliverables for each successive project, further promoting students' senses of autonomy.

At the end of the semester, all students were required to take a final examination per departmental policies and norms. The final examination was cumulative.

\subsection{Quantitative outcomes of IM2012}

The LCQ revealed that students perceived high levels of support (5.9 out of a possible 7.0) for their intrinsic motivation to learn from the instructors. These levels were significantly higher $(p<0.01)$ with a moderate effect size (Cohens $d=0.5$ ) when compared to previous traditional offerings of the course.

\subsection{Qualitative outcomes of IM2012}

Qualitative analysis of interviews with students from the course revealed that relatedness with their peers in collaborative learning was a primary support for students' intrinsic motivation to learn. In particular, students communicated that being able to work with peers on projects led to deeper and more personal learning. Additionally, the ability to choose teams and develop common commitments was critical in students' experience. In contrast, the required final examination was a main source of demotivation for the students. Students particularly cited a lack of a sense of competence for completing the final examination, in part because they perceived that they lacked prior experience in taking examinations in the course.

\section{Design and outcomes of IM2013}

The general structure of the IM course was maintained between 2012 and 2013. Students still completed projects in teams of four to five students with weekly consultation meeting and autonomy in their project-topic selection. Lectures were co-taught by two different instructors, including an award-winning instructor. Two primary changes were made to the course. First, the number of projects was reduced to two so that a midterm examination could be added to the course. The midterm examination was added to support students' sense of competence for the final examination. Second, the method for forming teams was changed. Rather than constructing 
teams based on students' project selections, teams were constructed using the CATME tool ${ }^{25,26}$. The CATME tool constructs teams to create diversify teams according to ability, group underrepresented minorities together so they feel better supported, and according to students' availability. With just these two changes, the overall fidelity of implementation was high. To support the development of team cohesion after being assembled through CATME, students were required to complete a team charter to establish ground rules and project topics.

\subsection{Quantitative Outcomes of IM2013}

Administration of the LCQ revealed a nearly identical climate score of 5.9, revealing no significant different $(\mathrm{p}=0.9)$ between the two offerings' climate. This result indicates that students perceived similar levels of support for their intrinsic motivation from the instructors.

\subsection{Qualitative Outcomes of IM2013}

In contrast to IM2012, interviews of students from IM 2013 revealed that students did not feel supported in their sense of relatedness from their team members. This lack of relatedness was revealed through several themes emerging from the student interviews which may also have contributed to the courses' failure to increase intrinsic motivation. First, students mainly expressed apathetic views toward the team charter, a requirement intended to promote autonomy and relatedness through working toward common goals. Second, a pervasive attitude of apathy characterized the teams' choice of project and team leader. Third, low levels of relatedness were and high levels of extrinsic motivation were exhibited within team dynamics. Opinions on teamwork in general were negative prior to team formation. Even teams that attempted to improve their team functioning did not succeed. Last, teams tended to choose a method of delegation of individual tasks rather than functioning together as a team. These four themes may have contributed to the lack of relatedness and autonomy observed.

\subsubsection{Apathetic views toward the team charter activity}

According to the original study, the team charter was a means to provide a support and structural mechanism for aiding team performance ${ }^{27}$. In that study, the majority of students indicated that the team charter assignment was useful and aided their team's performance ${ }^{27}$. Our interviews revealed a mixed result. In our study, seven out of the ten students interviewed explained the team charter in an apathetic view. They said that they did not take the team charter seriously or thought it was not valuable. They saw it as an assignment that just needed to be completed without much thought.

Well, in all honesty, our team charter, we didn't take it very seriously. We thought the whole concept, in general, was common sense. So we verbally said we'll write down some stuff we think our teachers wanted to see. I mean, basically we will be reasonable, we will do our work. As a whole that's what we wrote on our team charter. I don't think on our team charter was terribly valuable as a general in [CompE I] as a whole. (Student B)

The team charter we wrote down at the beginning and none of us really knew what to put on it, so we put the words from the suggested list. It wasn't very meaningful at that point to us. It was just an assignment we had to do, and we didn't really put much thought into 
it later on the semester. We just uploaded it because that was what we were supposed to do. (Student C)

However, six students explained that the team charter was more useful in setting expectations or making sure team members do their share of the work, which aligned with the team charter's objective in enabling each team "to develop and understand the rules of conduct expected of each team member ${ }^{27}$."

We also plan- started planning our team charter which was just a contract agreement between people in the group... I'd say it was fairly helpful. Just uh you know all those points just pre-establish- get all the expectations out of the way, what people were expecting to do. (Student F)

\subsubsection{Ambivalence concerning choice of project and team leader}

Several students expressed individual interest in selecting a certain project type; however, they chose not to share their ideas with the group, assuming others' interests lay elsewhere. Rather than demanding that other members comply with his or her project idea, team members seemed to adopt an ambivalent attitude toward project choice. In the following quote, a student decided not to share his idea for fear of other members not contributing enough for the project to be feasible. If groups were formed based on interest rather than schedule, a common purpose could have been established. This sense of purpose could help support relatedness among team members, perhaps encouraging students or increasing students' willingness to share their own project ideas with other team members with similar interests.

I'm kind of a software guy and it's really easy for me to do in my head, but that's very high level, but if you want to do something low level on a machine, you need to use simple functions. So in my research I realized it was possible, but everyone had to work on it, so that's why I decided not to mention this idea, because I knew not everyone would contribute a lot on it, and so I chose not to mention it. (Student A)

Students' statements illuminated the concept of team members being extrinsically motivated by course requirements or by professor approval. Instead of choosing to be creative, they chose something from the list of projects which is guaranteed to be "acceptable" in the eyes of the professors. They also displayed the extrinsic motivation of wanting to "impress the professors.” The team members were focused on impressing the professor rather than coming up with a project that would be intrinsically intriguing. Based on students' accounts, it seems the project was chosen out of a love for achieving rather than a love for electrical engineering itself. The following quotes demonstrate students' extrinsic motivation in terms of project choice.

So we got together and the first meeting outside of the designated meeting with TA time, we just started drawing out what the project would be, and none of us felt terribly creative so we picked something from the list. (Student C)

It was something that would impress the professors and it was just pretty much- it was a good idea and no one could think of anything better. (Student F) 
Similar to the selection of a leader and the conceptualization of the team charter, students also expressed apathy in terms of choosing a project. In fact, students stated that they felt other students didn't care about their projects. Again, it is possible that the apathy and lack of caring exhibited by students may be influenced by a lack of relatedness and purpose resulting from groups being created around students' schedules rather than their interests. A lack of purpose surrounding group projects may have been replaced by a common group goal unrelated to the particular project at hand. Specifically, a common goal that teams seemed to espouse was to maintain group harmony by not expressing individual suggestions or opinions on project topics. Students demonstrated a lack of caring and a lack of relatedness as well as expressing that project choice was of an arbitrary nature.

I think it was that, "Sure why not?" Like, they sounded fine or whatever, but I think in reality it was a very apathetic like, "I don’t care about the project.” (Student H)

I think we all were hesitant to choose a topic because we were all like, "Oh I don't really care, you guys can pick," and everyone had that kind of mindset so the literally we were just all, like, in a deadlock situation where, like, you know, "Someone pick, we don't care honestly." So then eventually we all just decided; someone decided on the calculator and then he was like, “Oh, I think it’s 'cuz it's the easiest? I don't know about you guys.” And everyone was like, "Yeah if you say- if you say so. Someone picked already. We'll choose it." So someone made their- the decision- and then everyone just followed through. (Student J)

Students' reactions to selecting a team leader were similar to their attitudes expressed about constructing and using the team charter. When students were faced with the task of deciding upon a team leader, there was a notable sense of ambivalence and even avoidance among team members.

Yeah, we really didn't care who was the leader as we didn't know each other. (Student A)

Everyone else was pretty passive and I've had lots of leadership opportunities through, you know, my years here in different organizations and I've always been one that - I enjoyed leading. It's not really something that is awkward or hard for me. And so I just said, "I'll do it if nobody else wants to," and they were all, "Okay, cool, that's awesome." (Student I)

It was again, no one wanted to do it. Everyone’s like, "Someone just step up, you know, we'll follow you." (Student J)

This pattern of apathy may have been influenced by a lack of relatedness created among team members. The dearth in relatedness expressed within teams may be a result of team members being chosen mainly according to their schedules rather than being determined by common interests. The lack of a common goal or purpose, in turn, may have contributed to the ambivalence of team members. In sum, instead of electing a leader capable of organizing, directing, or unifying the group, team members seemed to mainly be motivated by project requirements to elect a leader. 


\subsubsection{Assigned teams created negative perceptions of team dynamics}

Even before teams were assigned, it was evident that students came in with a negative view of team projects. Students predicted problems of miscommunication and issues with uncommitted team members. Though students had the choice of choosing projects, they perceived that they had little control over the outcome of the project if teams were assigned to them.

I was very not enthused about that [project teams], because teamwork, especially when you don't get to pick your teammates, it often results in a lot of friction and miscommunications because everyone's expectations on how teamwork will go are completely different. There is a huge range. Some people, either because they aren't that good at the material or because they don't really care, they aren't going to contribute whether they want to or not, whether they can or not. Some people know exactly what they are doing and what exactly needs to happen, and they'll do either everything for the team or they will get really frustrated. So it can cause a lot of friction for the team so I wasn't excited. (Student C)

It was a little- I was a bit worried because it’s really luck of the draw. Never know who you're getting. You could end up with people who don't pull their weight. I lucked out and got a pretty good team overall. Usually I'm used to being the guy who carries the team and does everything. (Student F)

When team members weren't making good progress, students would offer help. They would either ask the team if they needed help or tried to keep members accountable by pushing them to finish their work on time. But students expressed that their efforts to improve team dynamics felt futile as the problem persisted with no improvements.

During that time [first project] our communication was very slow and inefficient, so for me I was not happy with that. If you didn't finish your work or if you had trouble with that, you should let me know, since I was asking, but no one responded to me, I had no idea, so I assumed they were all good. I've worked on other projects in my high school, I know that something like this could happen. In every team there is unique personality of the team, so I guess that's our group personality... [The professor] had us evaluate our first project. That's when the communication issue was brought up, but even though we talked through it, nobody is actually doing it. (Student A)

So- but as far as being- I mean - the two people that did things you know I was fine with and it was awesome. The two people that didn't, you know like I said, in my opinion, it was their loss and we got it done on time and you know, I pushed them as much as I could without being annoying and as a leader, and you know maybe I was annoying but you know I kept trying to get them to do things and assigning them to parts, and then they wouldn't do it or they would try to do it and not know how to do it so somebody else would jump in and take over. (Student I)

This sense of poor team dynamic may have been due to the "I don't care" mentality seen previously concerning project choice. Students took less ownership for their projects with their 
apathy and team members may have felt that it was okay to not care much for the duration of their projects.

Yeah, I don’t think anybody really cared [about what project we chose]... One of the kids was like, "I just like software and hate hardware,” and so kind of had that view upfront. He’s like, "I don’t know how much help I'm going to be," so he already kind of checked himself out, and so he's just kind of along for the ride, and then one of the kids was in a fraternity and a master at helping- err having other people do his work... He's very apathetic, too, I guess. And so there just wasn't a lot of ideas or what were interests. It was just kind of like, "You have to get it done, I don’t really care.” (Student H)

The evidence of team apathy revealed a structural flaw regarding the aspect of autonomy in choosing projects. Though students had the freedom to choose a project, they were limited by the opinions of their teammates. One student's response illustrated this well. Though the project idea was intrinsically motivating, the student felt discouraged in proposing a project idea.

"So in my research I realized [picture manipulation] was possible, but everyone had to work on it, so that's why I decided not to mention this idea, because I knew not everyone would contribute a lot on it, and so I chose not to mention it. I tried to come up with other ideas. Because I was busy too, I only had a few ideas... It would have been great [if we did my idea]. I would be happy, but other than that, I guess I would give my teammates a lot of trouble.” (Student A)

\subsubsection{Delegation in place of teamwork}

Students specifically mentioned splitting up projects into pieces and never necessarily working together as a team. The delegation of tasks occurred in such a way that limited teammate interactions. This reflects a lack of relatedness, neglecting the process of working together to integrate individual aspects of the project and sharing knowledge. In essence, team members did not engage in teamwork; instead, they completed what amounts to individual projects. In fact, the following student quotes depict teamwork as a last resort or even go as far as expressing an interest in not working together at all.

In some instances, groups assigned one specific team member the individual task of "putting all the pieces together." Interestingly, in the quote from Student D below, the student says, "projects” that need to be merged instead of thinking of it as one, unified project with various components. This perfectly demonstrates how students conceptualized the group project as something to divide to avoid teamwork, thus eliminating opportunities for positive relatedness within team experiences. As team members did not engage in a teamwork-based project experience, further opportunities for community-building and defining purpose as a group dwindled. They did not build meaningful relationships, common interest, or goals through teamwork. Students displayed low levels of purpose, focusing on extrinsic motivations such as project completion or achieving a good grade instead of intrinsic motivations such as the enjoyment or interest in the subject matter.

For a calculator, every function is independent, so we can just assign a function to each member, and you don't need to intervene with each other. (Student A) 
With his help he would merge the projects at the very end. He's the only person who had the know-how of how to do that. But aside from that we had to decide who's going to do what so that we could actually get the projects together and merge them. That was the biggest challenge. It wasn't even making the project itself. It was getting everyone to work. (Student D)

We gave time of two weeks to do it and then after that week we get together and put all the files together and then run it and then if it works, then yeah, but if it doesn't work then we have to work on together, like go through the beginning and ask each other how this works. (Student E)

The theme of working individually rather than as a team shows how a lack of relatedness not only resulted in a divided project, but often left one member to learn how to put all the pieces together by himself. Student J calls it a "very bad thing," no doubt feeling little to no support or relatedness, having to piece individual project parts together by himself. The lack of support paints a picture of the lack of community and caring of other team members.

And then by the end, by the end of the first week, they just- everyone just sends everything to me and so I said I was going to be the one putting it together, but then, no one really gave me any documentation or hints about their stuff worked. So that was a very bad thing. I had to figure out everything on- by myself. (Student J)

We split it up among pieces, gave it to one person then compiled it to the final proposal (Student F)

We broke them down into individual portions and we went separate ways. (Student G)

There was one notable exception to groups working on an individual basis (without teamwork). The following group spent time together in-person. According to the student's description, they displayed increased levels of collaboration and relatedness compared to other groups. Interestingly, Student I (quoted below) made the most mentions of intrinsic motivation compared to all other students interviewed.

Like I said, two times a week for two to three hours each time and we would work on it in one of the labs. And the reason we did that was if somebody got stuck, we could just say, "Hey, come over here. How should I do this?” or "What do you think of this?” or "How can I fix this? I’m having trouble with this.” And so we would just help each other problem solve and that seemed to work pretty well. I mean we made pretty good progress. (Student I)

\section{Discussion and Conclusions}

There were only three main differences between the design of IM2012 and IM2013 courses: the change in instructors, the CATME tool $^{26}$ in assigning teams, and the inclusion of a midterm examination (resulting in one less project). Interviews with IM2013 students revealed contrary results to that of students in IM2012 regarding the increase of relatedness through teamwork. Most interviews of IM2013 described a lack of relatedness between students and their team, despite efforts to support autonomy and relatedness. However, students in both 
courses indicated strong support for their intrinsic motivation to learn from instructors as indicated by the LCQ scores.

The combination of these two results suggests that students' decreased relatedness and motivation from teamwork was caused by the switch from composing teams by project choice to composing teams with the CATME tool ${ }^{26}$. Though the CATME scheduling tool was designed to help create diverse teams based on ability, demographics, and available time, the CATME tool lacked the ability to group teams based on project preferences or other choices. The creation of project teams was seen as "random" or controlling rather than supporting students' autonomy. This lack of common project interest or initial autonomy may have caused students to be demotivated to invest into the functioning of their teams, undermining the development of relatedness with their peers. This lack of investment is most clear in the lack of effort or buy-in with the team charter.

Though the team charter's purpose was to help the development of the team to aid team performance, it was not as effective in producing team development as expected. The team charter's original objectives include providing students with a short team assignment from the start (support competence and purpose), helping members understand what is expected of each other (support relatedness), and allowing an early opportunity for members to get to know one another (support relatedness). The interviewed students did not perceive the team charter to be helpful in meeting these intended outcomes. The team charter was originally designed for business students, and therefore, may need to be reconsidered when used for engineering teams.

As for the midterm examination, few students mentioned it during the interview until the interviewer prompted the topic. Though the purpose of the midterm examination was to help students build competence in order to perform better on the final exam, students still felt that the final examination was difficult (and actually performed worse in the final examination in IM2013 when compared to IM2012). Unfortunately, providing only the one midterm examination did not seem to promote students’ sense of competence.

Although the course was designed to be autonomy-supportive and designed to increase students' levels of intrinsic motivation, students' accounts of the course indicated that it did not succeed in its primary goals of increasing intrinsic motivation and fostering autonomy within team settings. An analysis of aspects of the course such as the misuse of team charter, a luck-ofthe-draw attitude, patterns of leadership, as well as project negotiation and delegation revealed low levels of relatedness, autonomy, and intrinsic motivation during team-based activities. Future research should explore more deeply the differences in motivational outcomes for teams constructed around students' self-identified purpose and goals versus teams constructed by the instructor using research-based methods such as CATME.

\section{Acknowledgements}

This work was supported by the National Science Foundation under grant DUE-1140554. The opinions, findings, and conclusions do not necessarily reflect the views of the National Science Foundation or the author's institution. 


\section{References}

1. Borrego, M., \& Henderson, C. (2014). Increasing the use of evidence-based teaching in STEM higher education: A comparison of eight change strategies. Journal Of Engineering Education, 103(2), 220-252.

2. Felder, R. M., Brent, R., Prince, M. J. (2011). Effective instructional development strategies. Journal of Engineering Education, 100(1), 89-122.

3. Brownell, S., \& Tanner, K. (2012). Barriers to faculty pedagogical change: Lack of training, time, incentives, and tensions with professional identity. CBE-Life Sciences Education, 11, 339-346.

4. Hansen, E. J. (2012) Idea-based learning: A course design process to promote conceptual understanding. Stylus Publishing, LCC..

5. Wiggins, G. P., McTighe, J., Kiernan, L. J., \& Frost, F. (1998). Understanding by design. Alexandria, VA: Association for Supervision and Curriculum Development.

6. Litzinger, T., Lattuca, L., Hadgraft, R., \& Newstetter, W. (2011). Engineering education and the development of expertise. Journal Of Engineering Education, 100(1), 123-150.

7. Crouch, C. H. \& Mazur, E. (2001). Peer instruction: Ten years of experience and results. American Journal of Physics, 69(9), 970-977.

8. Ogilvie, C. A. (2009). Changes in students' problem-solving strategies in a course that includes context-rich, multifaceted problems. Physical Review Special Topics - Physics Education Research, 5(2), 1-14.

9. Lochhead, J., \& Whimbey, A. (1987). Teaching analytical reasoning through thinking aloud pair problem solving. In Developing Critical Thinking and Problem-Solving Abilities, ed. Stice, J. E., New Directions for Teaching and Learning, 30, San Francisco: Jossey-Bass, San Francisco.

10. McDowell, C., Werner, L., Bullock, H. E., \& Fernald, J. (2006). Pair programming improves student retention, confidence, and program quality. Communications of ACM, 49(8), 90-95.

11. Prince, M. (2004). Does active learning work? A review of the research. Journal of Engineering Education, 93(3), 223-231.

12. Smith, K. A., Sheppard, S. D., Johnson, D. W., \& Johnson, R. T. (2005). Pedagogies of engagement: Classroombased practices. Journal of Engineering Education, 94(1), 87-101.

13. Goldberg, D. E., Herman, G. L., Stolk, J. D., \& Somerville, M. (2011). Toward routine, low-cost intrinsic motivation course conversion, 2011 Symposium on Engineering and Liberal Education, Union College.

14. Ryan, R. M., \& Deci, E. L. (2000). Self-determination theory and the facilitation of intrinsic motivation, social development, and well-being. American Psychologist, 55, 68-78.

15. Ryan, R. M., \& Deci, E. L. (2002). Overview of self-determination theory: An organismic dialectical perspective, In Handbook of self-determination research, pp. 3-33. University of Rochester Press, Rochester, NY.

16. Pintrich, P. R. (2003). A motivational science perspective on the role of student motivation in learning and teaching contexts. Journal of Educational Psychology, 95(4), 667-686. 
17. Pink, D. H. (2011). Drive: The surprising truth about what motivates us. Riverhead Trade, New York.

18. Husman, J., Benson, L., \& Brem, S. (2010). Mini workshop - Understanding motivation in research and practice. In Proceedings of the $40^{\text {th }}$ ASEE/IEEE Frontiers in Education Conference. (pp. F4A-1 to F4A-2). Washington D.C. October 27-30.

19. Herman, G. L., Goldberg, D. E., Green, K., \& Somerville, M. (2012). Creating low-cost intrinsic motivation course conversions in a large required engineering course, In Proceedings of the 2012 American Society for Engineering Education Annual Conference and Exposition, (pp. AC2012-3730). San Antonio, TX. June $10-13$.

20. Clandinin, D. J., \& Connelly, F. M. (2000). Narrative inquiry: Experience and story in qualitative research, Jossey-Bass, San Francisco, CA.

21. Case, J. M., \& Light, G. (2011). Emerging methodologies in engineering education research, Journal of Engineering Education, 100(1), 186-210.

22. Spradley, J. P. (1980). Participant Observation, Holt, Rinehart \& Winston, New York, NY.

23. Robson, C. (2002). Real World Research, Blackwell, Malden, MA.

24. Joychelovitch, S., \& Bauer, M. W. (2000). Narrative interviewing, in M. W. Bauer and G. Gaskell (eds). Qualitative researching with text, image and sound: A practical handbook, Sage, London, 57-74.

25. Layton, R. A., Loughry, M. L., Ohland, M. W., \& Ricco, G. D. (2010). Design and validation of a web-based system for assigning members to teams using instructor-specified criteria. Advances in Engineering Education, 2(1), 1-28.

26. Ohland, M.W., Loughry, M.L., Woehr, D.J., Finelli, C.J., Bullard, L.G., Felder, R.M., Layton, R.A., Pomeranz, H.R., \& Schmucker, D.G. (2012). The comprehensive assessment of team member effectiveness: Development of a behaviorally anchored rating scale for self and peer evaluation. Academy of Management Learning \& Education, 11(4), 609-630.

27. Cox, P. L., \& Bobrowski, P. E. (2000). The team charter assignment: Improving the effectiveness of classroom teams. Journal of Behavioral and Applied Management, 1, 92-103. 